\title{
Glycemic carbohydrate and body weight regulation
}

Citation for published version (APA):

Saris, W. H. M. (2003). Glycemic carbohydrate and body weight regulation. Nutrition Reviews, 61(5 Pt 2), S10-S16. https://doi.org/10.1301/nr.2003.may.S10-S16

Document status and date:

Published: 01/01/2003

DOI:

10.1301/nr.2003.may.S10-S16

Document Version:

Publisher's PDF, also known as Version of record

\section{Please check the document version of this publication:}

- A submitted manuscript is the version of the article upon submission and before peer-review. There can be important differences between the submitted version and the official published version of record.

People interested in the research are advised to contact the author for the final version of the publication, or visit the DOI to the publisher's website.

- The final author version and the galley proof are versions of the publication after peer review.

- The final published version features the final layout of the paper including the volume, issue and page numbers.

Link to publication

\footnotetext{
General rights rights.

- You may freely distribute the URL identifying the publication in the public portal. please follow below link for the End User Agreement:

www.umlib.nl/taverne-license

Take down policy

If you believe that this document breaches copyright please contact us at:

repository@maastrichtuniversity.nl

providing details and we will investigate your claim.
}

Copyright and moral rights for the publications made accessible in the public portal are retained by the authors and/or other copyright owners and it is a condition of accessing publications that users recognise and abide by the legal requirements associated with these

- Users may download and print one copy of any publication from the public portal for the purpose of private study or research.

- You may not further distribute the material or use it for any profit-making activity or commercial gain

If the publication is distributed under the terms of Article $25 \mathrm{fa}$ of the Dutch Copyright Act, indicated by the "Taverne" license above, 


\title{
Glycemic Carbohydrate and Body Weight Regulation
}

\author{
Wim H.M. Saris, M.D., Ph.D.
}

The purpose of this review is to examine the relationship between glycemic carbohydrate and its effect on body weight regulation. By contrast to fat, carbohydrate has a positive impact on energy intake, energy expenditure, and body weight control. Despite some debate about the role of the carbohydrate-to-fat ratio in the diet and the prevalence of obesity, metabolic studies show that diets high in fat are more likely to result in body weight gain than diets high in carbohydrate. So far there are no indications that carbohydrate classes differ greatly with respect to energy expenditure and energy balance. However, the impact of carbohydrate source and class, as well as the form in which carbohydrate is consumed (i.e., solid or liquid) on body weight control requires further consideration.

(c) 2003 International Life Sciences Institute

doi: 10.131/nr.2003.may.S10-S16

Key words: glycemic carbohydrate, body weight regulation

\section{Introduction}

The high, and still increasing, prevalence of obesity in affluent societies as well as in developing countries is of concern because of relationships between obesity and major health hazards. Calculations indicate that the prevalence of type 2 diabetes mellitus will rise dramatically in the next decade owing to the increasing prevalence of obesity. ${ }^{1}$ At this moment, the total costs of obesityassociated diseases comprise an estimated four to seven percent of all healthcare expenditures in several developed countries. ${ }^{1}$

Apart from genetic factors, obesity is the result of an imbalance between food intake and daily physical activity. Efforts to reduce the prevalence of obesity have focused on three particular factors, namely, increasing levels of daily physical activity, reducing total fat intake,

Dr. Saris is with the Nutrition and Toxicology Research Institute, NUTRIM, University of Maastricht, P.O. Box 616, 6200 MD Maastricht, The Netherlands. and reducing intake of sugars and rapidly digested carbohydrates.

Taking public action to increase the level of daily physical activity in all sectors of the population is widely accepted. However, with respect to the dietary factorstotal fat intake and glycemic carbohydrates-there is much more debate in the literature. Throughout the 1960s and 1970s there was a tendency for some nutritionists to consider carbohydrates (especially sugar) an important factor for weight gain. Since then, attention has shifted towards fat as the major nutritional component promoting excess energy intake and weight gain. ${ }^{2}$

Dietary carbohydrate has been generally viewed as a beneficial nutrient with reference to weight control. ${ }^{3}$ This was based on accumulating evidence that energy balance could only be achieved though macronutrient balance, ${ }^{4}$ which requires that net oxidation of each nutrient equals the intake of the same macronutrient in the diet. Evidence that the regulation of the carbohydrate balance has a much higher priority in the metabolic hierarchy compared with fat, as well as the knowledge that de novo lipogenesis is limited, has contributed to the general perception that carbohydrate ingestion is less likely to promote fat storage. ${ }^{5}$ Furthermore large-scale epidemiologic studies associating dietary carbohydrate with a protective effect against body weight gain and obesity became more convincing.

Epidemiologic studies have observed an inverse relationship between carbohydrate intake, in particular, sugar, and prevalence of obesity. ${ }^{6}$ In general, there was a negative relationship between percent energy from fat and from sugars. This inverse relationship has been called the "fat-sugar seesaw." The reciprocal relationship between dietary sugar and fat was further said to be a causal one, such that any attempt to limit sucrose intake would result in a corresponding increase in fat consumption. Accordingly, dietary guidelines to reduce the consumption of fat as well as sugar were considered by some investigators as being mutually exclusive. ${ }^{7}$

Others showed that elevated consumption of added sugar was associated with a higher consumption of fats in confectionery and sweets. ${ }^{8}$ They concluded that without dietary sugar, most of the fat would not be consumed. ${ }^{8}$ This study initiated an interesting discussion 
about the role of sugar in the diet as well as in the maintenance of body weight. ${ }^{9-12}$

Despite controversy about the particular role of sugar, the message regarding fat's contribution to excess energy intake became stronger and led to recommendations for reducing fat intake in all dietary guidelines in the western world. The food industry rapidly expanded their low-fat offerings in the 1990s. ${ }^{13}$ Based on subjects reporting their own food intakes, fat intake has reduced significantly over the last decade. ${ }^{14}$ Surveys of consumer attitudes and intentions clearly showed a trend towards a low-fat diet. ${ }^{15}$ Although a number of meta-analyses of studies on the relationship between low-fat diets and body weight control showed that dietary fat intake is directly associated with obesity; scientific evidence of the relation between dietary fat content, the carbohydrate-to-fat ratio, and the prevalence of obesity has been challenged in recent years. ${ }^{16,17}$ For example, Katan et al. questioned the importance of low-fat, high-carbohydrate diets in the prevention and treatment of obesity. ${ }^{18}$ Randomized controlled trials show only very limited weight reduction and the so-called "fat paradox" can be seen in several countries in which there is a poor association between dietary fat intake and percentage of the population that is overweight. A direct relation between dietary fat and energy density was also questioned on the basis that many low-fat foods that are currently available are based on sugar or high-glycemic carbohydrates, which lead to energy density values similar to those of their high-fat counterparts. ${ }^{19}$

In the following these issues are addressed in more detail. Are all carbohydrates the same in relation to the energy balance? Do glycemic carbohydrates contribute to excess energy intake and weight gain?

\section{Energy Balance and Macronutrient Intake}

There is convincing evidence that the dietary macronutrient composition has important implications for body weight regulation. The scientific community generally accepts that protein and carbohydrate balance are regulated more closely than fat balance. ${ }^{20}$ There are a number of potential mechanisms to explain this effect. In metabolic terms, fat is more readily absorbed and assimilated into body fat stores and less rapidly oxidized than other macronutrients. In addition, satiety signals arising from fat ingestion are weaker and energy density per gram much higher than for carbohydrate. ${ }^{20}$

This may explain why when subjects are allowed to eat ad libitum over one day or longer, they consume more energy as the proportion of fat in the diet increases. This phenomenon has been described as "passive overconsumption," and was demonstrated in the well-controlled study by Stubbs et al. ${ }^{21}$ A group of male volunteers were allowed to eat ad libitum a diet with 20,40 , or
$60 \%$ of energy from fat for one week. On the $20 \%$ fat diet subjects experienced a modest decrease in body fat, whereas on the $60 \%$ fat diet, they gained approximately $0.5 \mathrm{~kg}$ body fat in seven days, owing to a considerable positive energy balance.

Isoenergetic substitution of fat with carbohydrate does not substantially change energy expenditure, although on theoretical grounds, it is expected to be lower, as was observed by Hill et al. ${ }^{22}$ Calculation of the thermic effect of food (TEF) in subjects consuming a $20 \%$-fat meal or a $60 \%$-fat meal composed of $10 \mathrm{MJ}$ resulted in a difference of only $\sim 120 \mathrm{~kJ} .^{20}$

Carbohydrates influence the thermogenic response. Blaak and Saris investigated the impact of oral ingestion of $75 \mathrm{~g}$ of glucose, fructose, sucrose, or starch on energy expenditure and postprandial substrate utilization for 6 hours in healthy volunteers. ${ }^{23}$ Integrated areas under the glucose and insulin response curves above baseline were highest with glucose and starch, intermediate with sucrose, and lowest with fructose (Figure 1). The total increment in energy expenditure above baseline was lowest for glucose and starch and highest for sucrose (Figure 1).

The differences in postingestive thermogenesis between these carbohydrates can be attributed to differences in metabolism. Because fructose avoids the first rate-limiting enzymes of glycolysis, it is metabolized more rapidly than glucose, resulting in the accumulation of three-carbon components available for gluconeogenesis and glycogen formation. Furthermore, the bioavailabity of fructose is probably low in the small intestine, leading to a lower thermogenic effect. Carbohydrate oxidation, glycogen formation, and the decrement in lipid oxidation have been reported to be higher after fructose, and to a lesser extent after sucrose, than after glucose ingestion. Previous studies have documented that the increase in energy expenditure and carbohydrate oxidation that normally accompanies glucose ingestion or glucose/insulin infusion is impaired in several insulinresistant states, including type 2 diabetes and obesity. ${ }^{24}$ On the basis of these studies, insulin is considered an important determinant of carbohydrate-induced thermogenesis. Other experiments indicate that insulin does not stimulate thermogenesis to any great extent, and that sympathetic nervous system stimulation could explain the TEF increase observed in glucose clamp experiments. ${ }^{25}$ The finding that fructose and sucrose ingestion results in a higher thermogenic response than glucose ingestion, despite the fact that fructose ingestion has only a slight effect on insulin secretion, indicates that that thermogenesis after carbohydrate ingestion is not directly related to the plasma insulin concentration.

It is difficult to extrapolate the above findings of the effect of acute carbohydrate ingestion on thermogenic 

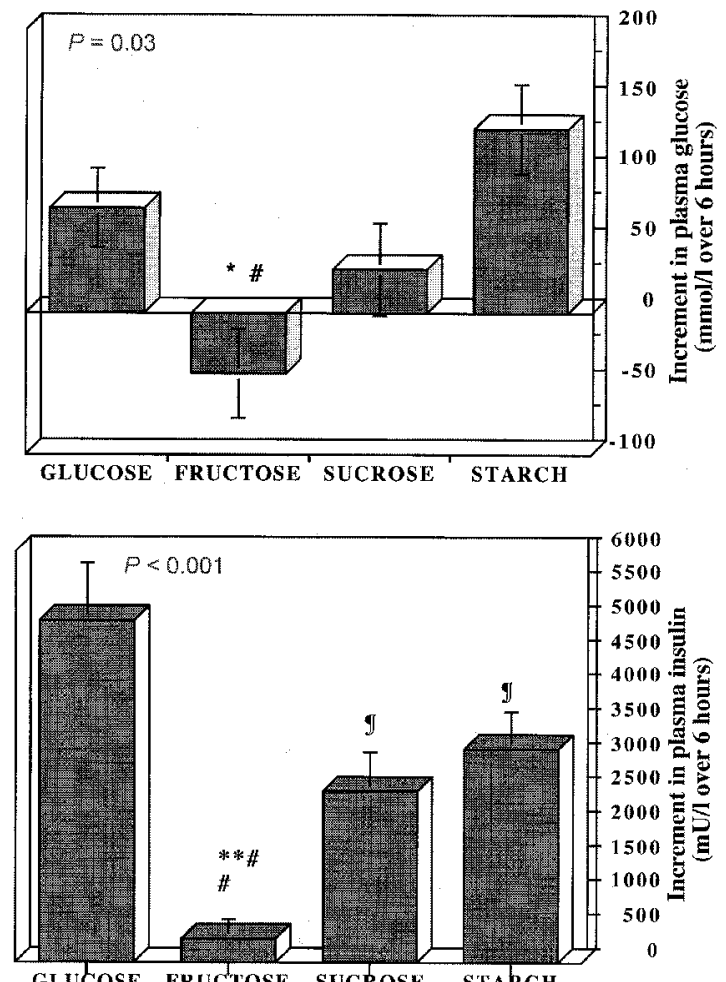

GLUCOSE FRUCTOSE SUCROSE STARCH

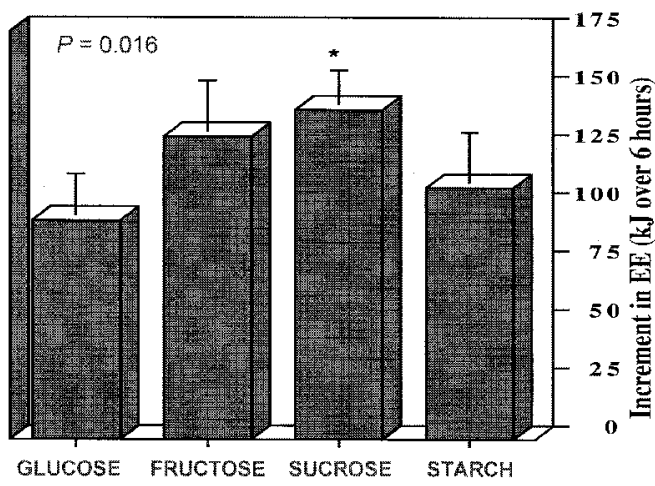

Figure 1. Integrated responses of plasma glucose, insulin, and energy expenditure (EE) above baseline for 6 hours after an orally ingested 75-g glucose, fructose, sucrose, or starch drink (reference 23$) . *=P<.05, * *=P<.01 \mathrm{v}$ glucose and starch ingestion, $\#=P<.05$, \#\# $=P<.01 \mathrm{v}$ sucrose ingestion.

response to a situation of long(er)-term energy or substrate balance. It can be speculated that the higher postprandial thermogenic responses after fructose or sucrose ingestion compared with glucose or starch ingestion may result in higher 24-hour energy expenditure. In addition, the higher increase in carbohydrate oxidation and more pronounced suppression of lipid oxidation with ingestion of glucose and starch may result in a larger effect on daily fat oxidation when glucose and starch are partly substituted by fructose and sucrose. However, evidence for differences in the effects of various carbohydrates on long-term energy or substrate balance is lacking.
These differences in TEF response are also of interest in relation to the discussion on low- and highglycemic carbohydrate foods and obesity. As reviewed by Anderson and Woodend, high-glycemic food with a higher insulin response reduces appetite and food intake in the short term (i.e., one hour), whereas the effect of low-glycemic food is delayed. ${ }^{26}$ Long-term monitoring of blood glucose levels indicate that glucose and insulin levels are not necessarily related to satiety and food intake but that dynamic declines in blood glucose levels are of importance to initiate a meal request. ${ }^{27}$

Several studies have compared the effects of different classes of carbohydrate on energy balance and rate of weight loss. Animal studies do not show differences among carbohydrate diets on energy expenditure, energetic efficiency, and energy partitioning during refeeding after low energy intake. These data, indicating no effect of the class of carbohydrate on energy balance, are consistent with studies in men. ${ }^{3}$ Three different types of hypocaloric diets (3, $4 \mathrm{MJ}$ ) for 3 weeks with either $45 \%$ energy from polysaccharides, $45 \%$ energy from sugars, or fat $(60 \%$ of energy), respectively, did not result in differences in the decrease in body weight, fat mass, and fat free mass were comparable. ${ }^{28}$

To study the impact of diet composition on energy balance, and to gain a better understanding of the difference in metabolic fat of various carbohydrates, it is necessary to eliminate the effect of appetite regulation by overfeeding. Horton et al. demonstrated that fat storage is higher with fat $(90-95 \%)$ than with carbohydrate (70-75\%) by overfeeding men for 14 days each with isoenergetic amounts of fat and carbohydrate. ${ }^{29}$ By contrast, and more recently reported, was the thermogenic response to overfeeding for 21 days with $5 \mathrm{MJ} /$ day of either a fat-rich (58\% of energy from fat) or a carbohydrate-rich $(78 \%$ of energy from high-sucrose carbohydrate) diet. ${ }^{30}$ No significant differences in fat deposition between the groups were observed. This finding is difficult to explain given the fact that earlier overfeeding studies with high carbohydrate levels have shown that the conversion of glucose to fat by de novo lipogenesis only occurs when oxidation is nearly completely covered by carbohydrate and glycogen stores are replete. The conversion from glucose to fat is energetically a very costly process that should lead to $\sim 20 \%$ lower fat deposition compared with fat deposition from fat. ${ }^{4}$ Astrup and Raben calculated that $68 \%$ more energy was required to gain $1 \mathrm{~kg}$ of body fat on the carbohydrate diet compared with the fat diet ( $155 \mathrm{MJ} / \mathrm{kg}$ vs. $42 \mathrm{MJ} / \mathrm{kg}$ ) on the basis of the data from Lammert et al. ${ }^{31}$ This confirms the notion of the extra thermogenic costs of converting glucose into fat for deposition in fat stores. Under normal circumstances this process of de novo lipogenesis is of limited significance in the deposition of excess carbohy- 
drate intake as fat. This leaves no other physiologic way than to increase carbohydrate oxidation and total energy expenditure.

\section{Glycemic Carbohydrates and Body Weight Control}

During the past 20 years, long-term intervention trials have shown that an increase in the carbohydrate-to-fat ratio in the diet has a positive effect on body weight control. Most cross-sectional studies linking carbohydrate intake expressed in energy percentage and body fatness expressed as body mass index (BMI, $\mathrm{kg} / \mathrm{m}^{2}$ ) show an inverse relation. ${ }^{5}$ Case-control studies of the dietary composition in obese and nonobese subjects mostly show a pattern of low carbohydrate intake in the obese. ${ }^{5}$ This inverse relationship seems even stronger for the intake of sugars and BMI. ${ }^{20}$ The top quintiles of sugars intake was associated with lower BMI. An analysis of the association between sucrose or carbohydrate intake with BMI showed an inverse relation between carbohydrate and BMI in eight out of nine studies. In four studies, for sucrose only, a significant inverse relation was found.

In all studies except one there is was corresponding positive association between percentage fat in the diet and BMI. This is surprising because only two out of nine studies found a positive correlation between energy intake and BMI. This information must be interpreted with caution; many studies have shown convincingly that especially obese subjects underreport their food intake. ${ }^{32}$ The percentage under-reporting appeared to be positively related to the BMI, ranging from 20 to $50 \%$ lower than their actual intakes.

Even more problematic is the selective under-reporting for macronutrients. With the increasing awareness of the relation between fat intake and disease risks, in particular, obesity, subjects are more likely to selectively under-report fatty foods. The high percentage of studies with a positive correlation between percent fat in the diet and BMI, as reviewed by Hill and Prentice, may be explained by the fact that these were published more then 10 years ago. ${ }^{20}$ In more recent surveys this finding is seen less frequently, but use of the doubly labeled water and the water balance technique to check for both underreporting and selective fat under-reporting has clearly demonstrated that both phenomena occurred in obese men. ${ }^{33}$ The reported percentage of energy from fat was a function of the level of under-reporting for energy intake. The selective under-reporting of fat could also partly explain the fat paradox as reviewed in the introduction. National health campaigns aimed at lowering fat intakes are thought to be successful because results from national food consumption surveys consistently have shown a decline in reported fat intake over the last 10 to 20 years.

Figure 2 shows the reported percentages of energy from fat of the national food consumption studies in the United States and the Netherlands, as well as the reported levels of fat intake by obese men (both uncorrected and corrected for under-reporting for energy and fat). ${ }^{33}$ The reported levels have been declining, but if under-reporting is considered, one must question the survey results

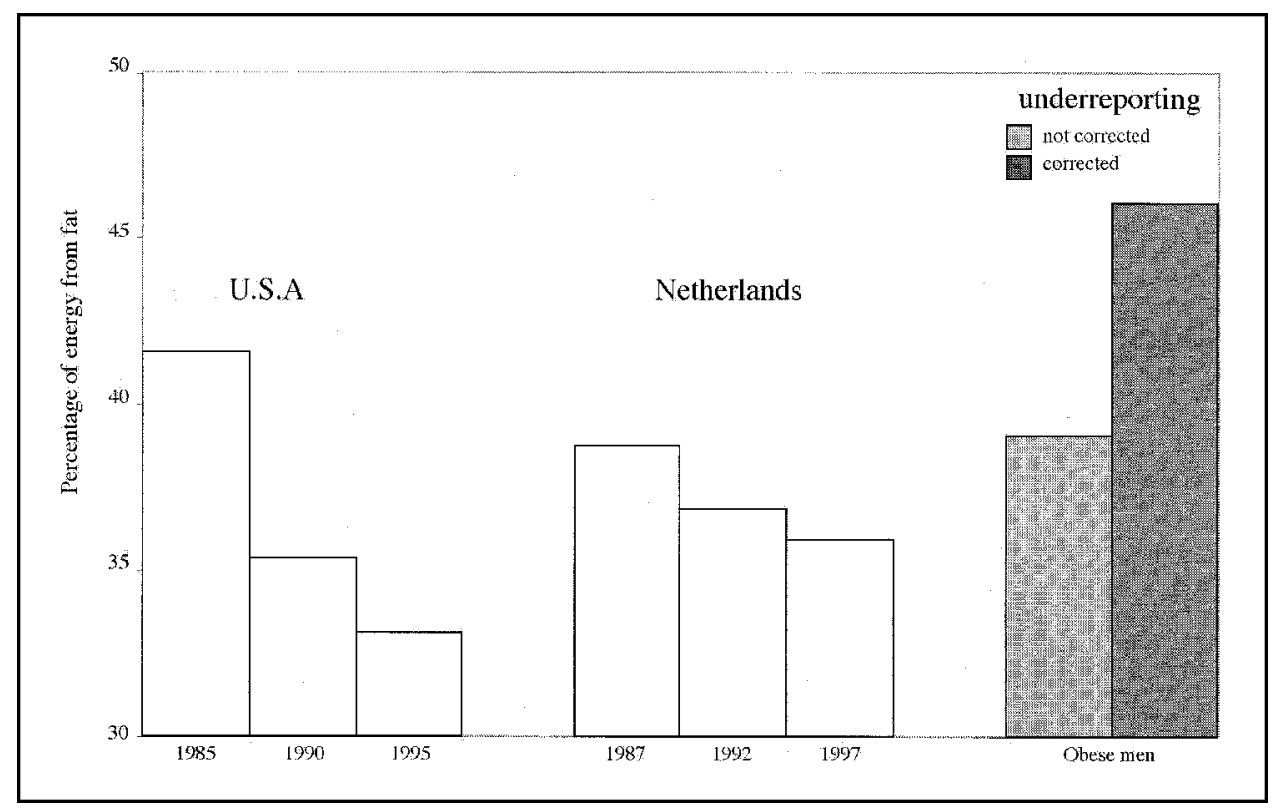

Figure 2. Percentages of energy from fat as measured in national food consumption studies (NHANES 1, 2, and 3) in 1985, 1990, and 1995; in the Netherlands in 1987, 1992, and 1997; and in obese men uncorrected and corrected for underreporting. Adapted from Goris et al. ${ }^{33}$ 
and the conclusion that fat consumption is declining. It is more likely that the combination of the exponential increase in obesity, especially in the United States, and the increasing awareness of the danger of fat in the diet resulted in selective under-reporting (Figure 2), thus explaining the fat paradox.

These observations on under-reporting strengthen confidence in the importance of a reduction in fat intake to control body weight as was concluded from the metaanalysis of ad libitum dietary intervention studies. ${ }^{17}$

So far, all long-term ad libitum randomized controlled intervention studies were focused on the carbohydrate-to-fat ratio and have not considered carbohydrate composition as an independent variable. Recently a randomized controlled trial called the CARMEN study was published that took into consideration the carbohydrate-to-fat ratio as well as the type of carbohydrate (simple vs. complex). ${ }^{34}$ In this multicenter study, moderately obese subjects were allocated to a seasonal control group with no intervention at all or to one of three experimental groups for 6 months: a control diet group, a low-fat, high-simple carbohydrate group (SCHO), or a low-fat, high-complex carbohydrate group (CCHO). To achieve and maintain compliance of food intake, the investigators used a validated shop system to give maximal control on food intake despite the fact that this was a long-term field study. Fat intake from the shop foods covered 65 to $77 \%$ of total fat intake in the different groups, whereas carbohydrate intake from the shop provided 65 to $67 \%$, with more variation in the specific carbohydrates depending on the type of intervention (SCHO received $57-78 \%$ of total energy from carbohydrate, $\mathrm{CCHO}$ received $56-74 \%$ of total energy as carbohydrate). In both low-fat dietary groups a significant decrease in body weight and body fatness was observed (Figure 3). Based on the observed reduction of fat intake, body weight reduction of $3.0 \mathrm{~kg}$ and $2.3 \mathrm{~kg}$ could be calculated for the SCHO and $\mathrm{CCHO}$ groups, respectively, using data from a meta-analysis of 28 clinical trials on the effect of low-fat diets. ${ }^{16}$

For the CCHO group this prediction was in line with the observed change, whereas for the SCHO group the reduction was approximately half of what could be expected. In both low-fat groups, however, the weight loss was significant compared with the control group (36\% of energy from fat).

As in most other low-fat trials, a steady state in body weight was reached in the randomized controlled trial after 4 months, demonstrating a new equilibrium in energy intake and expenditure. The observed gain in weight in long-term trials ( $>1$ year) is most likely related to the gradual deterioration of compliance, and not to compensatory mechanisms, as has been proposed by Willett; moreover, based on the observation that in trials

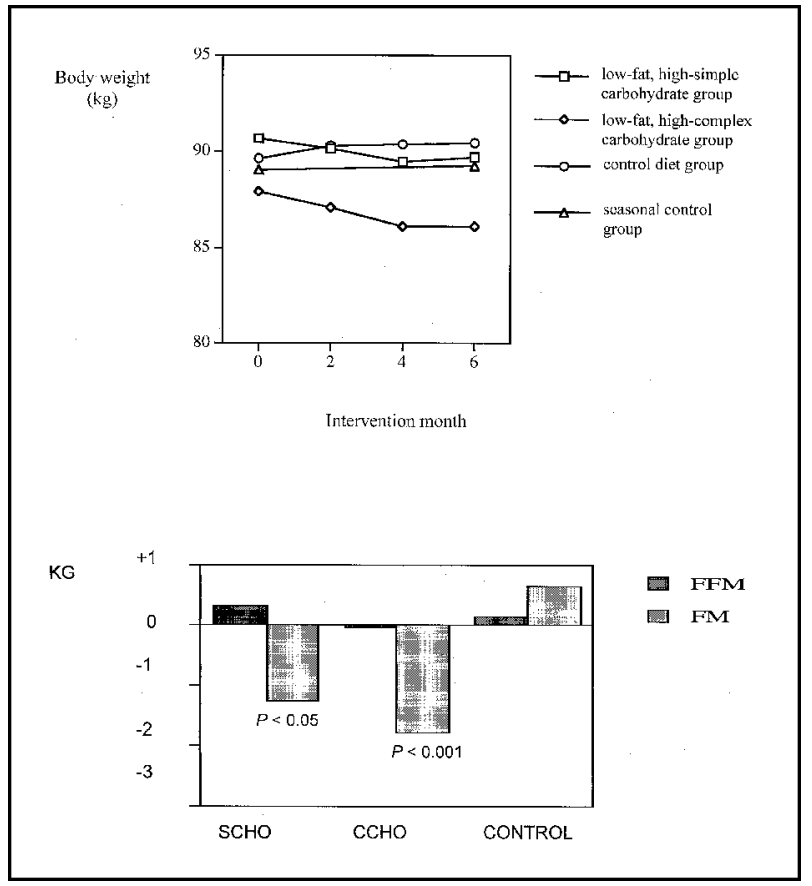

Figure 3. Mean body weight, fat-free mass (FFM), and fat mass (FM) changes during a 6-month randomized, controlled, multicenter dietary intervention trial, the CARMEN study (SCHO = low-fat, high-simple carbohydrate group, $\mathrm{CCHO}=$ low-fat, high-complex carbohydrate group, CONTROL = normal-fat and normal-carbohydrate group) (reference 34 ).

lasting one year or longer, fat consumption within the range of 18 to $40 \%$ of total energy has little, if any effect on body fatness. ${ }^{19}$ In addition, Willett argued that most of these randomized controlled trials might be confounded by difference in fiber content or in energy density. In the CARMEN study however, both experimental low-fat groups showed a similar fiber intake and decrease in energy density. ${ }^{34}$ The absence of fresh fruit and vegetables in the selection of the shop foods could explain the similar levels of fiber in the SCHO and $\mathrm{CCHO}$ groups. The comparable decrease in energy density in both the SCHO and CCHO groups is of interest because the replacement of fat by sugar or highly refined carbohydrates in low-fat foods is frequently said to lead to high-energy dense foods. The outcome of this study, with considerable use of low-fat, high-simple carbohydrate foods, does not confirm this claim. ${ }^{34}$

Although more randomized controlled trials are needed to confirm the results in this study on the effects of different classes of carbohydrates on long-term body weight control, the findings do show that there is little evidence that glycemic carbohydrate has a direct negative effect on energy balance and body weight control.

These results appear to conflict with a recently reported prospective observational study that suggested that for each additional serving of sugar-sweetened drinks consumed, BMI and prevalence of obesity significantly increased. ${ }^{35}$ 
Although there is no clear evidence that consumption of sugar per se affects food intake in a different manner compared with other types of carbohydrates, a meta-analysis of studies suggests that compensation at subsequent meals for energy consumed in the form of liquid might be less complete than for energy consumed in the form of solid food. ${ }^{36}$ Woodend and Anderson showed that a pure sugar beverage at different dosages does suppress food intake and appetite one hour later in a dose-dependent way. ${ }^{37}$

Further studies are urgently needed to determine whether glycemic carbohydrate contribute to weight gain because of the widespread availability of nondiet soft drinks in developed nations that are experiencing the epidemic of obesity. ${ }^{38}$

\section{Conclusion}

There is strong evidence that the carbohydrate content of the diet under ad libitum conditions plays an important role in body weight regulation. In particular, low-carbohydrate, high-fat diets promote overeating and weight gain. So far, there is little evidence that the type of carbohydrates (low glycemic and high glycemic) is of importance in relation to energy balance and weight control. Most epidemiologic studies have found a negative correlation between glycemic carbohydrate intake, in particular, sugar, and BMI. Thus, a high-carbohydrate intake may be crucial in preventing weight gain in individuals at risk of obesity. However, the impact of carbohydrate source and class, as well as the form in which carbohydrate is consumed (i.e., solid or liquid) requires further consideration.

1. World Health Organization. Obesity: prevention and managing the global epidemic. Geneva: WHO; 1998.

2. Lissner L, Heitman BL. Dietary fat and obesityevidence from epidemiology. Eur J Clin Nutr. 1995; 49:79-90.

3. Blaak EE, Saris WHM. Health aspects of various digestible carbohydrates. Nutr Res. 1995;15:15471573.

4. Flatt $\mathrm{J}$. The difference in the storage capacities for carbohydrate and for fat, and its implications in the regulation of body weight. Ann N Y Acad Sci. 1987; 499:104-123.

5. Astrup A, Raben A. Carbohydrate and obesity. Int J Obes. 1995;19:527-537.

6. Bolton-Smith C, Woodward M. Dietary composition and fat to sugar ratios in relation to obesity. Int $J$ Obes. 1994;8:820-828.

7. Gibney M, Sigmant-Grant M, Stanton JL, Keast DR. Consumption of sugar. Am J Clin Nutr. 1995;62: 178S-194S.

8. Emmett PM, Heaton $\mathrm{KW}$. Is extrinsic sugar a vehicle for dietary fat? Lancet. 1995;345:1537-1540.

9. Prentice AM, Jebb SA, Black AE. Extrinsic sugar as a vehicle for fat (letter). Lancet. 1995;346:695.
10. Gibney M. Is extrinsic sugar a vehicle for dietary fat (letter)? Lancet. 1995;346:695-696.

11. Macdiarmid JI, Cade JE, Blundell JE. Extrinsic sugar as a vehicle for fat (letter). Lancet. 1995;346: 696.

12. Heaton $\mathrm{KW}$, Emmett PM. Extrinsic sugar as vehicle for dietary fat (letter). Lancet. 1995;346:697-698.

13. Leveille M. Macronutrient substitutes, description and uses. Ann N Y Acad Sci. 1997;499:11-21.

14. Kennedy ET, Bowman SA, Powell R. Dietary fat intake in the US population. J Am Coll Nutr. 1999; 18:207-212.

15. Lloyd HM, Paisley CM, Mela DJ. Changing to a low-fat diet: attitudes and beliefs of UK consumers. Eur J Clin Nutr. 1993;47:361-373.

16. Bray GA, Popkin BM. Dietary fat intake does affect obesity. Am J Clin Nutr. 1998;68:1157-1173.

17. Astrup A, Grunwald GK, Melanson EL, Saris WHM, Hill JO. The role of low-fat diets in body weight control: a meta-analysis of ad libitum dietary intervention studies. Int J Obes. 2000;24:1545-1552.

18. Katan MB, Grundy SM, Willet WC. Beyond low-fat diets. N Engl J Med. 1997;337:563-566.

19. Willet WC. Is dietary fat a major determinant of body fat? Am J Clin Nutr. 1998;67:556S-562S.

20. Hill JO, Prentice AM. Sugar and body weight regulation. Am J Clin Nutr. 1995;62:2645-2745.

21. Stubbs RJ, Ritz P, Coward WA, Prentice AM. Covert manipulation of the ratio dietary fat to energy density: effect on food intake and energy balance in men feeding ad libitum. Am J Clin Nutr. 1995;62: 330-338.

22. Hill JO, Peters JC, Reed GW, Schlundt DG, Sharp T, Greene HL. Nutrient balance in humans: effects of diet composition. Am J Clin Nutr. 1991;54:10-17.

23. Blaak EE, Saris WHM. Postprandial thermogenesis and substrate utilization after ingestion of different dietary carbohydrates. Metabolism. 1996;45:12351242.

24. Ravussin E, Bogardus C, Schwartz RS, et al. Thermic effect of infused glucose and insulin in men. Decreased response with increased insulin resistance in obesity and non-insulin dependent diabetes mellitus. J Clin Invest. 1983;72:893-902.

25. Christin L, Nacht CA, Vernet O, Ravussin E, Jequier $\mathrm{E}$, Acheson K. Insulin in the thermic effect of glucose. J Clin Invest. 1986;92:1747-1755.

26. Anderson GH, Woodend D. Effect of glycemic carbohydrates on appetite and food intake. Nutr Rev. 2003;61:S17-S26.

27. Melanson KJ, Westerterp-Plantenga MS, Saris WHM, Smith FJ, Campfield LA. Blood glucose patterns and appetite in time-blinded humans: carbohydrate versus fat. Am J Physiol. 1999;277:R337R345.

28. Piatti PM, Pontiroli AR, Saibene A, et al. Insulin sensitivity and lipid levels in obese subjects after slimming diets with different complex and simple carbohydrate content. Int J Obes. 1993;17:375381.

29. Horton TJ, Drougas H, Brachey A. Fat and carbohydrate overfeeding in humans: different effects on energy storage. Am J Clin Nutr. 1955:62;19-29.

30. Lammert O, Grunnet N, Faber P, et al. Effects of 
isoenergetic overfeeding of either carbohydrate or fat in young men. Br J Nutr. 2000;84:233-245.

31. Astrup A, Raben A. Commentary: sugar as a slimming agent? Br J Nutr. 2000:84:585-587.

32. Schoeller DA. How accurate is self-reported dietary energy intake? Nutr Rev. 1990;48:373-379.

33. Goris AHC, Westerterp-Plantenga MS, Westerterp $\mathrm{KR}$. Undereating and underrecording of habitual food intake in obese men: selective under-reporting of fat intake. Am J Clin Nutr. 2000;71:130-134.

34. Saris WHM, Astrup A, Prentice AM, et al. Randomized controlled trial of changes in dietary carbohydrate/fat ratio and simple vs complex carbohydrates on body weight and blood lipids: the CARMEN study. Int J Obes. 2000;24:1310-1318.
35. Ludwig DS, Peterson KE, Gortmaker SL. Relation between consumption of sugar-sweetened drinks and childhood obesity: a prospective, observational analysis. Lancet. 2001;357:505-508.

36. Mattes RD. Dietary compensation by humans for supplemental energy provided as ethanol or carbohydrate in fluids. Physiol.Behav. 1996;59:179-187.

37. Woodend DM, Anderson GH. Effect of sucrose and safflower oil preloads on short term appetite and food intake of young men. Appetite. 2001;37:185195.

38. Johnson RK, Frary C. Choose beverage and foods to moderate your intake of sugars: the 2000 Dietary Guidelines for Americans-what's all the fuss about? J Nutr. 2001;131:2766S-2771S. 